Walhovd, Kristine B., et al. "Premises of plasticity-And the loneliness of the medial temporal lobe." Neurolmage (2015).

(C) 2013. This manuscript version is made available under the CC-BY-NC-ND 4.0 license http://creativecommons.org/licenses/by-nc-nd/4.0/ 
Premises of plasticity - and the loneliness of the medial temporal lobe

Kristine B Walhovd ${ }^{\mathrm{a}, b^{*}}$, René Westerhausen ${ }^{\mathrm{a}}$, Anne-Marie Glasø de Lange ${ }^{\mathrm{a}}$, Anne

Cecilie Sjøli Bråthen ${ }^{\mathrm{a}}$, Håkon Grydeland ${ }^{\mathrm{a}}$, Andreas Engvig ${ }^{\mathrm{c}}$, Anders M. Fjell ${ }^{\mathrm{a}}$

${ }^{a}$ Research Group for Lifespan Changes in Brain and Cognition, Department of Psychology, University of Oslo, 0373, Norway

${ }^{\mathrm{b}}$ Department of Physical medicine and rehabilitation, Unit of neuropsychology, Oslo University Hospital, 0424, Norway

${ }^{\mathrm{c}}$ Department of Medicine, Diakonhjemmet Hospital, Oslo, Norway

* Address correspondence to:

Kristine B Walhovd, Dept of Psychology, POB 1094 Blindern, 0317 Oslo, Norway, Phone: +47 228451 29, Fax: +47 228450 01, e-mail:

k.b.walhovd@psykologi.uio.no 


\begin{abstract}
In this perspective paper, we examine possible premises of plasticity in the neural substrates underlying cognitive change. We take the special role of the medial temporal lobe as an anchoring point, but also investigate characteristics throughout the cortex. Specifically, we examine the dimensions of evolutionary expansion, heritability, variability of morphometric change, and inter-individual variance in myelination with respect to the plastic potential of different brain regions. We argue that areas showing less evolutionary expansion, lower heritability, greater variability of cortical thickness change through the lifespan, and greater inter-individual differences in intracortical myelin content have a great extent of plasticity. While different regions of the brain show these features to varying extent, analyses converge on the medial temporal lobe including the hippocampi as the target of all these premises. We discuss implications for effects of training on brain structures, and conditions under which plasticity may be evoked.
\end{abstract}

Keywords: plasticity, medial temporal lobe, evolution, heritability, variability, myelin 
A number of studies have by now shown effects of experience, including physical and cognitive activity, on brain structure and function, e.g. (Bless et al., 2014; Engvig et al., 2010, 2012a; Erickson et al., 2014; Lovden et al., 2010b; Lovden et al., 2012). Effects vary with type of activity or training, as well as target group (Engvig et al., 2014; Engvig et al., 2012b; Wenger et al., 2012). In a lifespan perspective, however, a number of studies converge on the medial temporal lobe (MTL) areas as plastic and susceptible to intervention effects across ages (Carlson et al., 2015; Engvig et al., 2014; Lovden et al., 2012). The dentate gyrus of the hippocampus stands out as one restricted area in displaying neurogenesis in human adulthood ((Eriksson et al., 1998) but see also (Ernst et al., 2014; Lotsch et al., 2014)). Hippocampus and the entorhinal cortex have unique roles in learning involving episodic memory (Scoville and Milner, 1957) and navigation (Hafting et al., 2005). In this perspective paper we use the established role of the MTL to examine possible premises of plasticity in neural substrates underlying cognitive change, using published as well as preliminary data.

By premises therefore, we refer to both prerequisites (from Latin praemittere, to send before) and the ground or localization of plasticity in the brain (as in premises referring to a tract of land with the buildings thereon). Plasticity can also have multiple meanings, a common definition is capacity for being molded or altered (Merriam-Webster, 2015). Another definition is the capacity of organisms with the same genotype to vary in developmental pattern, in phenotype, or in behavior according to varying environmental conditions (Merriam-Webster, 2005). Clearly, many types of alterations take place in the brain, on highly different time scales, in response to variable environmental conditions. For the purpose of the present perspective paper, we restrict our focus from common rapid ongoing adaptation based 
on current function, by Lövden and colleagues termed flexibility, i.e. capacity to optimize the brain's performance within the limits of the current state of functional supply (Lovden et al., 2010a). Rather, we will focus on plasticity as comprising functional changes accompanied by structural alterations, capacity for reactive change altering the individual's range of functioning (Lovden et al., 2010a). Of further note, our perspective is not restricted to the type of reactive changes that are programmed to occur as individuals encounter species-mandatory experiences within critical periods, such as normal visual stimulation of the eyes in early development associated with cortical ocular dominance columns in mammals (Wiesel, 1982). While such experience-expectant plasticity can have dramatic consequences under abnormal environmental conditions in early development (Greenough et al., 1987), the lifelong experience-dependent plasticity is associated with more commonly occurring differences in experience, and is the primary target of this perspective paper.

Specifically, we examine the dimensions of evolutionary expansion, heritability, variability of morphometric change, and inter-individual variance in myelination with respect to plastic potential of brain areas. This perspective is based on the rationale that a possible conjunction of these characteristics can underlie plasticity-related brain mechanisms, and their interplay may be a key to enable cognitive changes. Hence we ask what characterizes the MTL on these dimensions, and to what extent the MTL shows these characteristics exclusively or shares them with other neuroanatomical structures. If the characteristics are shared among structures, to what extent can these other structures also display relatively high plasticity?

\section{Evolutionary expansion}


Alzheimer's Disease is likely a human-specific disease, being very uncommon in other primates (Bufill et al., 2013; Finch and Austad, 2012), and it has been suggested that evolutionarily high-expanding brain areas are especially susceptible to neurodegeneration and dementia (Rapoport and Nelson, 2011). For instance, much focus has been put on the default mode network (DMN), comprising frontal, parietal and lateral, as well as medial temporal areas (Buckner, 2004, 2012). Initially DMN was suggested to consist of association cortices having undergone especially large phylogenetic changes from nonhuman primates to humans, having the most complex columnar organization, and being slow in reaching mature levels of myelin (Andreasen et al., 1995; Catani and ffytche, 2005). However, as seen from Figure 1 (upper left panel), the medial temporal areas, including the hippocampus and entorhinal cortex, along with other parts of the limbic system such as the retrosplenial cortex, form important exceptions to this: They are not among the areas exhibiting the largest inter-primate expansion. Of note, in addition to these areas, we also see that the medial primary visual cortex shows relatively little expansion. While this is neither an area showing adult neurogenesis, nor bordering regions that do so, it is certainly an area of especially high plasticity in early life, when experience can irreversibly alter the organization of the primary visual cortex (Maya-Vetencourt and Origlia, 2012). Hence, certain areas that show high capacity for plasticity in humans also show relatively low inter-primate expansion.

Indeed the premise of the countless animal models on these regions, the MTL, hippocampus and entorhinal cortex inclusive, see e.g. (Hafting et al., 2005), is their considerable structural and functional similarity across species. Even in reptiles and fish, place memory and spatial mapping capabilities can be similarly based on the 
function of structures considered homologous to the hippocampus of mammals and birds, namely the medial cortex in reptiles and lateral telencephalic pallium in teleost fish (Salas et al., 2003). The same is true for the olfactory areas in the orbitofrontal cortex, with the olfactory bulb also having been found to display neurogenesis in adulthood in most mammals (Gheusi and Lledo, 2014). Though some differences prevail, there are considerable cross-species similarities of structure, and also in fruit flies (drosphila melanogaster), there is an analogous olfactory center, the antennal lobe (Vosshall, 2001). Although these similarities can be due both to conservation of structure, or convergent evolution (Gottfried and Zald, 2005), the correspondence of layout across very different organisms is striking, suggesting that these structures have evolved as “optimal solutions” to problems fundamental across organisms.

Hence, it seems that evolutionary expansion and high extent of phylogenetic change is not a premise of plasticity. Rather, we suggest that conservation or convergent evolution across species may be one. This should not come as a surprise when taking into account that human beings as a species have evolved as an adaptive advantage what may be seen as the counterpart of plasticity, the ability to rely heavily on accumulated experience (Rakic, 1985). As also noted by others, plasticity is costly to human beings (Lindenberger, 2014), and must be counterbalanced in the human central nervous system by considerable rigidity. Indeed, compared to many other species, we display little renewal of our brains. Enormous differences exist in neurogenic potential between "lower" and "higher" vertebrates (Zupanc, 2008). The relative number of new cells and neurogenic sites is much larger in teleost fish than in mammals. Fish brains produce new neurons in dozens of areas in addition to the homologues of the hippocampus and the olfactory bulb (Zupanc, 2006). Moreover, 
compared to many "lower" vertebrates, the rate of neurogenesis in adult mammals decreases with age (Amrein et al., 2011). Part of the limbic system, with the cingulum projections, MTL and the hippocampi, along with olfactory areas, are lonely "old” and fundamental structures in the human brain. Hence we suggest that in looking for premises and mechanisms of plasticity, we should look to our distant past, and cerebral features shared with other species, rather than to features uniquely human, as plasticity is not uniquely human, in fact not very human at all.

\section{Heritability}

Twin and family studies provide another line of research that can be taken to identify brain areas which may have shown high susceptibility to plastic changes beyond what can be explained by common genes in specific cohorts. In this line of reasoning, we first want to emphasize that we by this do not in any way imply that brain areas with high heritability cannot show plastic changes. Of that we know little, as heritability estimates are both highly malleable by environmental factors and bound to be specific to the sample and context in which they have been derived (Plomin et al., 2014). For example, body mass index has a high heritability (around .75), but is highly influenced and modifiable by differences in food intake and physical activity (Horn et al., 2015). A high heritability of e.g. cortical thickness in a specific region does not mean that cortical thickness in that region is hardwired and cannot be changed by environmental influence. We cannot use "what is" as an indication for "what could be" as Plomin and colleagues phrase it (Plomin et al., 2014). That is, we do not want to imply that high heritability is an indication for "what could not be" in terms of plastic changes. However, regions showing low heritability in multiple samples per 
definition have shown variance that cannot be explained by genetic variance, and where one can more often assume that environmental effects have been at work. We thus think, in conjunction with multiple dimensions, it may be fruitful to circle in on such areas also to identify regions that may be targets of plastic changes.

Candidate areas are brain regions for which the phenotypic structural variance can to a substantial degree be explained by environmental influence, that is, brain areas that have shown low heritability $\left(\mathrm{h}^{2}\right)$ or, expressed within the framework of the ACE-model (i.e., additive genetics, A; common environment, C; unique environment, E), low additive genetic effects ( $\left.\mathrm{a}^{2}\right)$. In general, heritability estimates for brain measures show substantial differences between brain regions (for review see (Batouli et al., 2014; Blokland et al., 2012; Jansen et al., 2015)). While different morphometric variables have been used, the most commonly considered are volume (e.g. of subcortical structures), along with cortical thickness, and that is also our focus here. For example, in a study by Eyler et al. ((Eyler et al., 2012) see also (Kremen et al., 2010)), using data from the Vietnam Era Twin Study of Aging (VETSA) project, heritability estimates of apparent cortical thickness vary between $\mathrm{h}^{2}=.50$ and .70 throughout frontal, parietal, occipital and temporal brain regions (see also Figure 1, upper right panel). The lowest heritability coefficients were found in right entorhinal $\left(\mathrm{h}^{2}=.42\right)$ and medial orbitofrontal $\left(\mathrm{h}^{2}=.44\right)$ cortex, parahippocampal gyrus $\left(h^{2}=.46\right)$ as well as in the banks of the superior temporal sulcus $\left(h^{2}=.43\right)$. Schmitt et al. (Schmitt et al., 2008), analyzing data from the National Institute of Mental Health (NIMH) twin sample, identify right lingual gyrus $\left(a^{2}=.01\right)$ as well as right 
and left parahippocampal gyrus $\left(\mathrm{a}^{2}=.06\right.$ and .10 , respectively) as the regions with lowest additive genetic effects on cortical thickness variance. Regarding the volume of subcortical gray matter structures, Kremen et al. (Kremen et al., 2010) report the heritability estimates for hippocampus $\left(a^{2}=.63-.64\right)$ and thalamus $\left(a^{2}=.60-.68\right)$ to be lower than estimates for caudate nucleus $\left(a^{2}=.70-.79\right)$ or putamen $\left(\mathrm{a}^{2}=.84-.85\right.$; VETSA sample; for comparable results in a Dutch twin sample see (den Braber et al., 2013)).

Heritability estimates of brain measures are not stable and rather follow a characteristic trajectory throughout the lifespan (for review see (Batouli et al., 2014)). During childhood and adolescence, heritability estimates of most brain structures continuously increase (Batouli et al., 2014; Schmitt et al., 2014; Swagerman et al., 2014), though with increasingly reduced increment during the second life decade (Schmitt et al., 2014). From the third decade of life onwards a continuous decline in heritability can be observed into older age (Batouli et al., 2014; Lessov-Schlaggar et al., 2012). For example, average $\mathrm{h}^{2}$ estimates across brain structures start at about .70 in infants, reach a peak of .85 during adolescence and fall continuously to a level of about .55 at the age of 65 years (Batouli et al., 2014). Also, the MTL regions appear to show lower heritability in adults with higher age, thus following the general trajectory of heritability during the lifespan, although the heritability estimates for the MTL at different ages appear moderate or somewhat lower compared with other subcortical and cortical regions (Batouli et al., 2014). 
Thus, taken together, the MTL region (i.e., entorhinal and parahippocampal cortex as well as hippocampal volume) appears to be among the brain regions that show lowest heritability across the lifespan, independent of study and sample (see also meta-analysis by (Blokland et al., 2012)). This observation may be influenced by multiple conditions, e.g. reliability of measures, but may also be seen indicative of a susceptibility of the MTL to environmental variance. We further discuss variability of change and possible mechanisms below.

Variability of morphometric change through the lifespan

To what extent does the MTL show greater intra-individual variability of change compared to other brain regions through the lifespan? As seen from Figures 1 (lower left panel) and 2, the MTL cortices and the hippocampus show considerable interindividual variability of change, and more so than most other structures. This variability may or may not be linked to lower heritability, as change in itself may be heritable (Schmitt et al., 2014; Swagerman et al., 2014), and mediated by the environment sought out by individuals with specific genetic dispositions. The greater variability may be linked to susceptibility of these areas to experience and various impacts. It has previously been suggested that regions characterized by a high degree of life-long plasticity are vulnerable to degeneration in aging (Fjell et al., 2014b; Lindenberger, 2014; Mesulam, 1999; Neill, 1995; Raz, 2007). The MTL is arguably among these structures (Eriksson et al., 1998), along with olfactory areas, also showing substantial variability and effects of age (Bhatnagar et al., 1987). Indeed, animal models indicate that regional susceptibility to anesthesia-induced apoptosis varies depending on age of exposure, but for brain regions undergoing neurogenesis 
into adulthood, namely the dentate gyrus and olfactory bulb, susceptibility extends into adulthood (Deng et al., 2014).

The extended neurogenesis of these areas may hence render immature neurons vulnerable to insult, but also, the general metabolic demands of these structures may put them at risk. Studies of regional glucose uptake have demonstrated that hippocampal neurons have among the highest energy requirements in the brain (LaManna and Harik, 1985; McEwen and Reagan, 2004). Cardiovascular and respiratory disease, as well as ischemic insult, may then more easily influence the functioning of these areas than that of regions lower in demand. Hence, it is important to recognize that while these areas are highly plastic, this plasticity may also be more easily compromised. Effects of cognitive interventions have been found in both healthy young and older adults in terms of hippocampal volumetric sparing or increase (Engvig et al., 2014; Lovden et al., 2012). However, while one study found that cortical increases were restricted to young adults (Wenger et al., 2012), we found that patients with subjective cognitive impairment showed cortical, but not hippocampal increases, which can be interpreted as possible compromise of hippocampal plasticity selectively (see Figure 3), as also seen in a functional MRI study (Belleville et al., 2011). In sum, the variability of change in the MTL may be due to differences in experience, health and disease factors. Due to the extended neurogenesis and high metabolic demands, this region may be especially susceptible to change, both in positive and negative terms (Eriksson et al., 1998; Mesulam, 1999; Neill, 1995). 
Substantial evidence points to white matter alterations as a result of training (see e.g. (Engvig et al., 2012a; Lovden et al., 2010b; Mackey et al., 2012; Scholz et al., 2009; Takeuchi et al., 2010)). For instance, we have shown that memory training in middleaged and older adults yielded increased fractional anisotropy (FA) in the uncinate fasciculus compared with controls, and that the extent of these changes was related to memory performance improvement (Engvig et al., 2012a). Such alterations in FA can be seen to reflect formation and remodeling of myelination of the long-distance axons within white matter tissue (Zatorre et al., 2012). However, there is also rich cellular evidence that the myelination of intracortical gray matter axons can be influenced by experience. Age-related alteration of glial cells in sensory cortical areas can be accelerated by activity-driven central mechanisms that result from an age-related loss of peripheral sensitivity (Tremblay et al., 2012). The human cerebral cortex contains numerous myelinated fibers and cortical myelin maturation and aging-related degradation are likely of great importance to brain functioning, as myelin serves to isolate axons and hence speed up the conduction of nerve signals (Bartzokis, 2004; Nieuwenhuys, 2013). Recently, surface-based cortical myelin has been mapped by taking the ratio of $\mathrm{T} 1$-weighted and $\mathrm{T} 2$-weighted $(\mathrm{T} 1 \mathrm{w} / \mathrm{T} 2 \mathrm{w})$ magnetic resonance image (MRI) intensities to correct for the MRI-related image intensity bias field and to increase the contrast-to-noise ratio for myelin (Glasser and Van Essen, 2011). Using a T1w/T2w -myelin-mapping approach, we have previously characterized the degree of intracortical myelin in individuals at different ages of the lifespan (Grydeland et al., 2013). We found inverse U-shaped lifespan trajectories, with substantial heterogeneity across different cortical regions. Association cortices tended to show the most curved trajectories, indicating protracted intracortical myelin development and vulnerability to aging. Myelin content correlated with within-subject 
variability on a speeded performance task signaling behavioral correlates of individual differences in cortical myelin (Grydeland et al., 2013). Hence, mapping myelin by use of T1w/T2w MRI could be a valuable tool for studying intra-cortical myelin content effects. For the present perspective paper, we therefore proceeded to map the inter-individual variability of myelin content in the cortices specifically. As seen from Figure 1 (lower right panel), the variability of myelin content is substantial, and is the highest in MTL, cingulate and primary visual cortices. We here argue that increased variability in the $\mathrm{T} 1 \mathrm{w} / \mathrm{T} 2 \mathrm{w}$ ratio is marker for the increased susceptibility of these regions for experience dependent changes.

Although myelin plasticity is an important mechanism, myelin and myelin-associated inhibitors are also implicated in reduced developmental plasticity (Takesian and Hensch, 2013), with high myelin content being related to more hard-wired and less plastic regions in the cortex, and previous research has suggested that myelin content is lower in regions high-expanding between humans and other primates (Amlien et al., 2014; Glasser and Van Essen, 2011). Interestingly, myelin-related processes seem to be a crucial factor for closing the window of plasticity in brain regions that are especially susceptible to environmental influences such as the visual cortex. It has been demonstrated in mice that mutations that interfere with normal myelin-related processing extend the critical period of plasticity in visual cortex, and that these processes normally function to consolidate the neural circuitry established during experience-dependent plasticity (McGee et al., 2005). Conversely, in the adult brain, it seems that regions with high content of myelin are more resistant to change. Myelin content in parahippocampal and entorhinal cortices is low (Grydeland et al., 2013), 
and combined with the large inter-individual variability in myelin content, this likely constitute a premise for plasticity of this region.

\section{Conclusion: Singling out the loner}

We proposed as possible premises of plasticity of brain structures, that they exhibit relatively lower evolutionary expansion, can show lower heritability and greater variability of morphometric change and inter-individual variance in myelin content. Seeing these data in conjunction across cortical areas, as shown in the conjunction map in Figure 1 (center), leads us to one region exhibiting all characteristics, namely the entorhinal cortex, extending into the parahippocampal cortex, of the parahippocampal gyrus. While we have not been able to use the conjunction approach of cortical evolutionary expansion, heritability and variability of myelination on subcortical structures such as the hippocampus, we know from much comparative data that the hippocampus too is evolutionarily old, has across multiple studies shown relatively low variability, and shows an extended myelination, making inter-individual variability likely. Importantly, our analysis of volumetric change in the hippocampus shows extensive variability (Figure 2). Hence, evidence from evolutionary expansion, heritability, variability of change and myelination arguably converge on the medial temporal lobe. We believe that interventions to some extent may have preferentially large effects on these areas, and may hence also be targeted at these areas. However, MTL plasticity may also be preferentially vulnerable, such as e.g. in Alzheimer's Disease and its preclinical stages (Mesulam, 1999; Neill, 1995). For instance, as seen in Figure 3, an intensive memory intervention failed to induce training-related hippocampal changes in patients with memory 
complaints, whereas some neocortical areas retained potential for plasticity as measured by increased gray matter volume. In case of compromised MTL plasticity, then, one may look to other areas that show combinations of the dimensions examined here. This could be areas that have shown either relatively lower evolutionary expansion, such as the insula and in part orbitofrontal cortex; lower heritability, such as part of the orbitofrontal cortex and cingulate; greater variability of change, such as wide regions of the frontal and in part parietal cortex, or greater variability of myelination, such as the cingulate cortex. Indeed, intervention effects have been found in all of these areas, e.g. (Engvig et al., 2010; Engvig et al., 2014). This perspective paper contains preliminary data, and our suggestions are tentative, but we believe that further research into these dimensions and their convergence as possible premises of plasticity may be a fruitful approach. 


\section{Figure Captions}

\section{Figure 1 Conjunction map - the medial temporal lobe is alone}

Upper left panel: Cortical area expansion was assessed between several Simian primates, i.e. marmoset, macaque and human, and the expansion maps were averaged, yielding regions of consistently high vs. consistently low expansion across species. MTL shows consistently low degrees of expansion across primates. Data from (Chaplin et al., 2013), analyzed as described in (Amlien et al., 2014; Fjell et al., 2014a).

Upper right panel: The genetic correlation between thickness measured at each vertex on the cortical surface and total cortical thickness. MTL shows the lowest genetic correlations. The scale goes from .50 to .99. Results from the Vietnam Era Twin Study of Aging (VERSA), published in (Eyler et al., 2012).

Lower left panel: Variability in longitudinal cortical thickness change (standard deviation / mean) was measured in 593 participants and mapped to the cortical surface. MTL is among the regions with the highest degree of inter-individual variability in longitudinal thickness change.

Lower right panel: Variability in intra-cortical myelin content, calculated from T1 weighted / T2 weighted contrast within the cortex. MTL shows high degree of interindividual variability in myelin content. Data from (Grydeland et al., 2013).

\section{Figure 2 Hippocampal change variability}

Inter-individual variability in change (std/ mean) was calculated for representative subcortical structures. Hippocampus shows the largest inter-individual variability in change. The data material is described in (Storsve et al., 2014). 
Figure 3 Differential effects of cognitive intervention on the hippocampus and the cortex in healthy elderly and patients with memory complaints

Panel A: Eight weeks of memory training caused relative increase in cortical volume in healthy elderly and patients with subjective cognitive impairment (SCI) compared to a non-training group of age-matched healthy elderly. The training effect was seen in several regions of the cortex, including the entorhinal. Panel B: While training had similar effects on cortical changes in healthy elderly and SCI patients (e.g., in the frontal cortex as shown in the boxplot to the right), comparable effects on hippocampus was not seen. Only healthy elderly showed benefits of cognitive training on hippocampal volume change, while the SCI patients did not improve relative to the non-training healthy elderly. Figure modified from (Engvig et al., 2014). 


\section{Acknowledgements}

This work was supported by the European Research Council’s Starting Grant scheme

(to K.B.W project number 313440 and A.M.F. project number 283634) and the Norwegian Research Council (to K.B.W., A.M.F.). 


\section{References}

Amlien, I.K., Fjell, A.M., Tamnes, C.K., Grydeland, H., Krogsrud, S.K., Chaplin, T.A., Rosa, M.G., Walhovd, K.B., 2014. Organizing Principles of Human Cortical Development-Thickness and Area from 4 to 30 Years: Insights from Comparative Primate Neuroanatomy. Cereb Cortex.

Amrein, I., Isler, K., Lipp, H.P., 2011. Comparing adult hippocampal neurogenesis in mammalian species and orders: influence of chronological age and life history stage. Eur J Neurosci 34, 978-987.

Andreasen, N.C., O'Leary, D.S., Cizadlo, T., Arndt, S., Rezai, K., Watkins, G.L., Ponto, L.L., Hichwa, R.D., 1995. Remembering the past: two facets of episodic memory explored with positron emission tomography. Am J Psychiatry 152, 1576-1585. Bartzokis, G., 2004. Age-related myelin breakdown: a developmental model of cognitive decline and Alzheimer's disease. Neurobiol Aging 25, 5-18; author reply 49-62.

Batouli, S.A., Trollor, J.N., Wen, W., Sachdev, P.S., 2014. The heritability of volumes of brain structures and its relationship to age: a review of twin and family studies. Ageing Res Rev 13, 1-9.

Belleville, S., Clement, F., Mellah, S., Gilbert, B., Fontaine, F., Gauthier, S., 2011. Training-related brain plasticity in subjects at risk of developing Alzheimer's disease. Brain 134, 1623-1634.

Bhatnagar, K.P., Kennedy, R.C., Baron, G., Greenberg, R.A., 1987. Number of mitral cells and the bulb volume in the aging human olfactory bulb: a quantitative morphological study. Anat Rec 218, 73-87.

Bless, J.J., Westerhausen, R., Kompus, K., Gudmundsen, M., Hugdahl, K., 2014. Selfsupervised, mobile-application based cognitive training of auditory attention: A behavioral and fMRI evaluation. Internet Interventions 1, 102-110.

Blokland, G.A., de Zubicaray, G.I., McMahon, K.L., Wright, M.J., 2012. Genetic and environmental influences on neuroimaging phenotypes: a meta-analytical perspective on twin imaging studies. Twin Res Hum Genet 15, 351-371.

Buckner, R.L., 2004. Memory and executive function in aging and AD: multiple factors that cause decline and reserve factors that compensate. Neuron 44, 195208.

Buckner, R.L., 2012. The serendipitous discovery of the brain's default network. Neuroimage 62, 1137-1145.

Bufill, E., Blesa, R., Augusti, J., 2013. Alzheimer's disease: an evolutionary approach. J Anthropol Sci.

Carlson, M.C., Kuo, J.H., Chuang, Y.F., Varma, V.R., Harris, G., Albert, M.S., Erickson, K.I., Kramer, A.F., Parisi, J.M., Xue, Q.L., Tan, E.J., Tanner, E.K., Gross, A.L., Seeman, T.E., Gruenewald, T.L., McGill, S., Rebok, G.W., Fried, L.P., 2015. Impact of the Baltimore Experience Corps Trial on cortical and hippocampal volumes.

Alzheimers Dement.

Catani, M., ffytche, D.H., 2005. The rises and falls of disconnection syndromes. Brain 128, 2224-2239.

Chaplin, T.A., Yu, H.H., Soares, J.G., Gattass, R., Rosa, M.G., 2013. A conserved pattern of differential expansion of cortical areas in simian primates. J Neurosci 33, 15120-15125.

den Braber, A., Bohlken, M.M., Brouwer, R.M., van 't Ent, D., Kanai, R., Kahn, R.S., de Geus, E.J., Hulshoff Pol, H.E., Boomsma, D.I., 2013. Heritability of subcortical 
brain measures: a perspective for future genome-wide association studies. Neuroimage 83, 98-102.

Deng, M., Hofacer, R.D., Jiang, C., Joseph, B., Hughes, E.A., Jia, B., Danzer, S.C., Loepke, A.W., 2014. Brain regional vulnerability to anaesthesia-induced neuroapoptosis shifts with age at exposure and extends into adulthood for some regions. Br J Anaesth 113, 443-451.

Engvig, A., Fjell, A.M., Westlye, L.T., Moberget, T., Sundseth, O., Larsen, V.A., Walhovd, K.B., 2010. Effects of memory training on cortical thickness in the elderly. Neuroimage 52, 1667-1676.

Engvig, A., Fjell, A.M., Westlye, L.T., Moberget, T., Sundseth, O., Larsen, V.A., Walhovd, K.B., 2012a. Memory training impacts short-term changes in aging white matter: a longitudinal diffusion tensor imaging study. Hum Brain Mapp 33, 2390-2406.

Engvig, A., Fjell, A.M., Westlye, L.T., Skaane, N.V., Dale, A.M., Holland, D., DueTonnessen, P., Sundseth, O., Walhovd, K.B., 2014. Effects of cognitive training on gray matter volumes in memory clinic patients with subjective memory impairment. J Alzheimers Dis 41, 779-791.

Engvig, A., Fjell, A.M., Westlye, L.T., Skaane, N.V., Sundseth, O., Walhovd, K.B., 2012b. Hippocampal subfield volumes correlate with memory training benefit in subjective memory impairment. Neuroimage 61, 188-194.

Erickson, K.I., Leckie, R.L., Weinstein, A.M., 2014. Physical activity, fitness, and gray matter volume. Neurobiol Aging 35 Suppl 2, S20-28.

Eriksson, P.S., Perfilieva, E., Bjork-Eriksson, T., Alborn, A.M., Nordborg, C., Peterson, D.A., Gage, F.H., 1998. Neurogenesis in the adult human hippocampus. Nat Med 4, 1313-1317.

Ernst, A., Alkass, K., Bernard, S., Salehpour, M., Perl, S., Tisdale, J., Possnert, G., Druid, H., Frisen, J., 2014. Neurogenesis in the striatum of the adult human brain. Cell 156, 1072-1083.

Eyler, L.T., Chen, C.H., Panizzon, M.S., Fennema-Notestine, C., Neale, M.C., Jak, A., Jernigan, T.L., Fischl, B., Franz, C.E., Lyons, M.J., Grant, M., Prom-Wormley, E., Seidman, L.J., Tsuang, M.T., Fiecas, M.J., Dale, A.M., Kremen, W.S., 2012. A comparison of heritability maps of cortical surface area and thickness and the influence of adjustment for whole brain measures: a magnetic resonance imaging twin study. Twin Res Hum Genet 15, 304-314.

Finch, C.E., Austad, S.N., 2012. Primate aging in the mammalian scheme: the puzzle of extreme variation in brain aging. Age (Dordr) 34, 1075-1091. Fjell, A.M., Amlien, I.K., Sneve, M.H., Grydeland, H., Tamnes, C.K., Chaplin, T.A., Rosa, M.G., Walhovd, K.B., 2014a. The Roots of Alzheimer's Disease: Are HighExpanding Cortical Areas Preferentially Targeted? Cereb Cortex.

Fjell, A.M., McEvoy, L., Holland, D., Dale, A.M., Walhovd, K.B., Alzheimer's Disease Neuroimaging, I., 2014b. What is normal in normal aging? Effects of aging, amyloid and Alzheimer's disease on the cerebral cortex and the hippocampus. Prog Neurobiol 117, 20-40.

Gheusi, G., Lledo, P.M., 2014. Adult neurogenesis in the olfactory system shapes odor memory and perception. Prog Brain Res 208, 157-175.

Glasser, M.F., Van Essen, D.C., 2011. Mapping human cortical areas in vivo based on myelin content as revealed by T1- and T2-weighted MRI. J Neurosci 31, 11597-11616. 
Gottfried, J.A., Zald, D.H., 2005. On the scent of human olfactory orbitofrontal cortex: meta-analysis and comparison to non-human primates. Brain Res Brain Res Rev 50, 287-304.

Greenough, W.T., Black, J.E., Wallace, C.S., 1987. Experience and brain development. Child Dev 58, 539-559.

Grydeland, H., Walhovd, K.B., Tamnes, C.K., Westlye, L.T., Fjell, A.M., 2013. Intracortical myelin links with performance variability across the human lifespan: results from T1- and T2-weighted MRI myelin mapping and diffusion tensor imaging. J Neurosci 33, 18618-18630.

Hafting, T., Fyhn, M., Molden, S., Moser, M.B., Moser, E.I., 2005. Microstructure of a spatial map in the entorhinal cortex. Nature 436, 801-806.

Horn, E.E., Turkheimer, E., Strachan, E., Duncan, G.E., 2015. Behavioral and Environmental Modification of the Genetic Influence on Body Mass Index: A Twin Study. Behav Genet 45, 409-426.

Jansen, A.G., Mous, S.E., White, T., Posthuma, D., Polderman, T.J., 2015. What twin studies tell us about the heritability of brain development, morphology, and function: a review. Neuropsychol Rev 25, 27-46.

Kremen, W.S., Prom-Wormley, E., Panizzon, M.S., Eyler, L.T., Fischl, B., Neale, M.C., Franz, C.E., Lyons, M.J., Pacheco, J., Perry, M.E., Stevens, A., Schmitt, J.E., Grant, M.D., Seidman, L.J., Thermenos, H.W., Tsuang, M.T., Eisen, S.A., Dale, A.M., Fennema-Notestine, C., 2010. Genetic and environmental influences on the size of specific brain regions in midlife: the VETSA MRI study. Neuroimage 49, 12131223.

LaManna, J.C., Harik, S.I., 1985. Regional comparisons of brain glucose influx. Brain Res 326, 299-305.

Lessov-Schlaggar, C.N., Hardin, J., DeCarli, C., Krasnow, R.E., Reed, T., Wolf, P.A., Swan, G.E., Carmelli, D., 2012. Longitudinal genetic analysis of brain volumes in normal elderly male twins. Neurobiol Aging 33, 636-644.

Lindenberger, U., 2014. Human cognitive aging: corriger la fortune? Science 346, 572-578.

Lotsch, J., Schaeffeler, E., Mittelbronn, M., Winter, S., Gudziol, V., Schwarzacher, S.W., Hummel, T., Doehring, A., Schwab, M., Ultsch, A., 2014. Functional genomics suggest neurogenesis in the adult human olfactory bulb. Brain Struct Funct 219, 1991-2000.

Lovden, M., Backman, L., Lindenberger, U., Schaefer, S., Schmiedek, F., 2010a. A theoretical framework for the study of adult cognitive plasticity. Psychol Bull 136, 659-676.

Lovden, M., Bodammer, N.C., Kuhn, S., Kaufmann, J., Schutze, H., Tempelmann, C., Heinze, H.J., Duzel, E., Schmiedek, F., Lindenberger, U., 2010b. Experiencedependent plasticity of white-matter microstructure extends into old age. Neuropsychologia 48, 3878-3883.

Lovden, M., Schaefer, S., Noack, H., Bodammer, N.C., Kuhn, S., Heinze, H.J., Duzel, E., Backman, L., Lindenberger, U., 2012. Spatial navigation training protects the hippocampus against age-related changes during early and late adulthood. Neurobiol Aging 33, 620 e629-620 e622.

Mackey, A.P., Whitaker, K.J., Bunge, S.A., 2012. Experience-dependent plasticity in white matter microstructure: reasoning training alters structural connectivity. Front Neuroanat 6, 32. 
Maya-Vetencourt, J.F., Origlia, N., 2012. Visual cortex plasticity: a complex interplay of genetic and environmental influences. Neural Plast 2012, 631965.

McEwen, B.S., Reagan, L.P., 2004. Glucose transporter expression in the central nervous system: relationship to synaptic function. Eur J Pharmacol 490, 13-24. McGee, A.W., Yang, Y., Fischer, Q.S., Daw, N.W., Strittmatter, S.M., 2005. Experience-driven plasticity of visual cortex limited by myelin and Nogo receptor. Science 309, 2222-2226.

Merriam-Webster, 2005. Merriam-Webster's Medical Desk Dictionary In: Merriam-Webster (Ed.). Merriam-Webster, Incorporated, Springfield, MA. Merriam-Webster, 2015. Merriam-Webster Online Dictionary. In: MerriamWebster (Ed.). Merriam-Webster, Incorporated, Springfield, MA.

Mesulam, M.M., 1999. Neuroplasticity failure in Alzheimer's disease: bridging the gap between plaques and tangles. Neuron 24, 521-529.

Neill, D., 1995. Alzheimer's disease: maladaptive synaptoplasticity hypothesis. Neurodegeneration 4, 217-232.

Nieuwenhuys, R., 2013. The myeloarchitectonic studies on the human cerebral cortex of the Vogt-Vogt school, and their significance for the interpretation of functional neuroimaging data. Brain Struct Funct 218, 303-352.

Plomin, R., Colledge, E., 2001. Genetics and psychology: Beyond heritability. . European Psychologist 6, 229-240.

Plomin, R., Shakeshaft, N.G., McMillan, A., Trzaskowski, M., 2014. Nature, Nurture, and Expertise. Intelligence 45, 46-59.

Rakic, P., 1985. Limits of neurogenesis in primates. Science 227, 1054-1056. Rapoport, S.I., Nelson, P.T., 2011. Biomarkers and evolution in Alzheimer disease. Prog Neurobiol 95, 510-513.

Raz, N., 2007. Comment on Greenwood (2007): Which side of plasticity? Neuropsychology 21, 676-677; discussion 680-673.

Salas, C., Broglio, C., Rodriguez, F., 2003. Evolution of forebrain and spatial cognition in vertebrates: conservation across diversity. Brain Behav Evol 62, 7282.

Schmitt, J.E., Lenroot, R.K., Wallace, G.L., Ordaz, S., Taylor, K.N., Kabani, N., Greenstein, D., Lerch, J.P., Kendler, K.S., Neale, M.C., Giedd, J.N., 2008. Identification of genetically mediated cortical networks: a multivariate study of pediatric twins and siblings. Cereb Cortex 18, 1737-1747.

Schmitt, J.E., Neale, M.C., Fassassi, B., Perez, J., Lenroot, R.K., Wells, E.M., Giedd, J.N., 2014. The dynamic role of genetics on cortical patterning during childhood and adolescence. Proc Natl Acad Sci U S A 111, 6774-6779.

Scholz, J., Klein, M.C., Behrens, T.E., Johansen-Berg, H., 2009. Training induces changes in white-matter architecture. Nat Neurosci 12, 1370-1371.

Scoville, W.B., Milner, B., 1957. Loss of recent memory after bilateral hippocampal lesions. J Neurol Neurosurg Psychiatry 20, 11-21.

Storsve, A.B., Fjell, A.M., Tamnes, C.K., Westlye, L.T., Overbye, K., Aasland, H.W., Walhovd, K.B., 2014. Differential longitudinal changes in cortical thickness, surface area and volume across the adult life span: regions of accelerating and decelerating change. J Neurosci 34, 8488-8498.

Swagerman, S.C., Brouwer, R.M., de Geus, E.J., Hulshoff Pol, H.E., Boomsma, D.I., 2014. Development and heritability of subcortical brain volumes at ages 9 and 12. Genes Brain Behav 13, 733-742. 
Takesian, A.E., Hensch, T.K., 2013. Balancing plasticity/stability across brain development. Prog Brain Res 207, 3-34.

Takeuchi, H., Sekiguchi, A., Taki, Y., Yokoyama, S., Yomogida, Y., Komuro, N., Yamanouchi, T., Suzuki, S., Kawashima, R., 2010. Training of working memory impacts structural connectivity. J Neurosci 30, 3297-3303.

Tremblay, M.E., Zettel, M.L., Ison, J.R., Allen, P.D., Majewska, A.K., 2012. Effects of aging and sensory loss on glial cells in mouse visual and auditory cortices. Glia 60, 541-558.

Vosshall, L.B., 2001. The molecular logic of olfaction in Drosophila. Chem Senses 26, 207-213.

Wenger, E., Schaefer, S., Noack, H., Kuhn, S., Martensson, J., Heinze, H.J., Duzel, E., Backman, L., Lindenberger, U., Lovden, M., 2012. Cortical thickness changes following spatial navigation training in adulthood and aging. Neuroimage 59, 3389-3397.

Wiesel, T.N., 1982. Postnatal development of the visual cortex and the influence of environment. Nature 299, 583-591.

Zatorre, R.J., Fields, R.D., Johansen-Berg, H., 2012. Plasticity in gray and white: neuroimaging changes in brain structure during learning. Nat Neurosci 15, 528536.

Zupanc, G.K., 2006. Neurogenesis and neuronal regeneration in the adult fish brain. J Comp Physiol A Neuroethol Sens Neural Behav Physiol 192, 649-670. Zupanc, G.K., 2008. Adult neurogenesis and neuronal regeneration in the brain of teleost fish. J Physiol Paris 102, 357-373. 

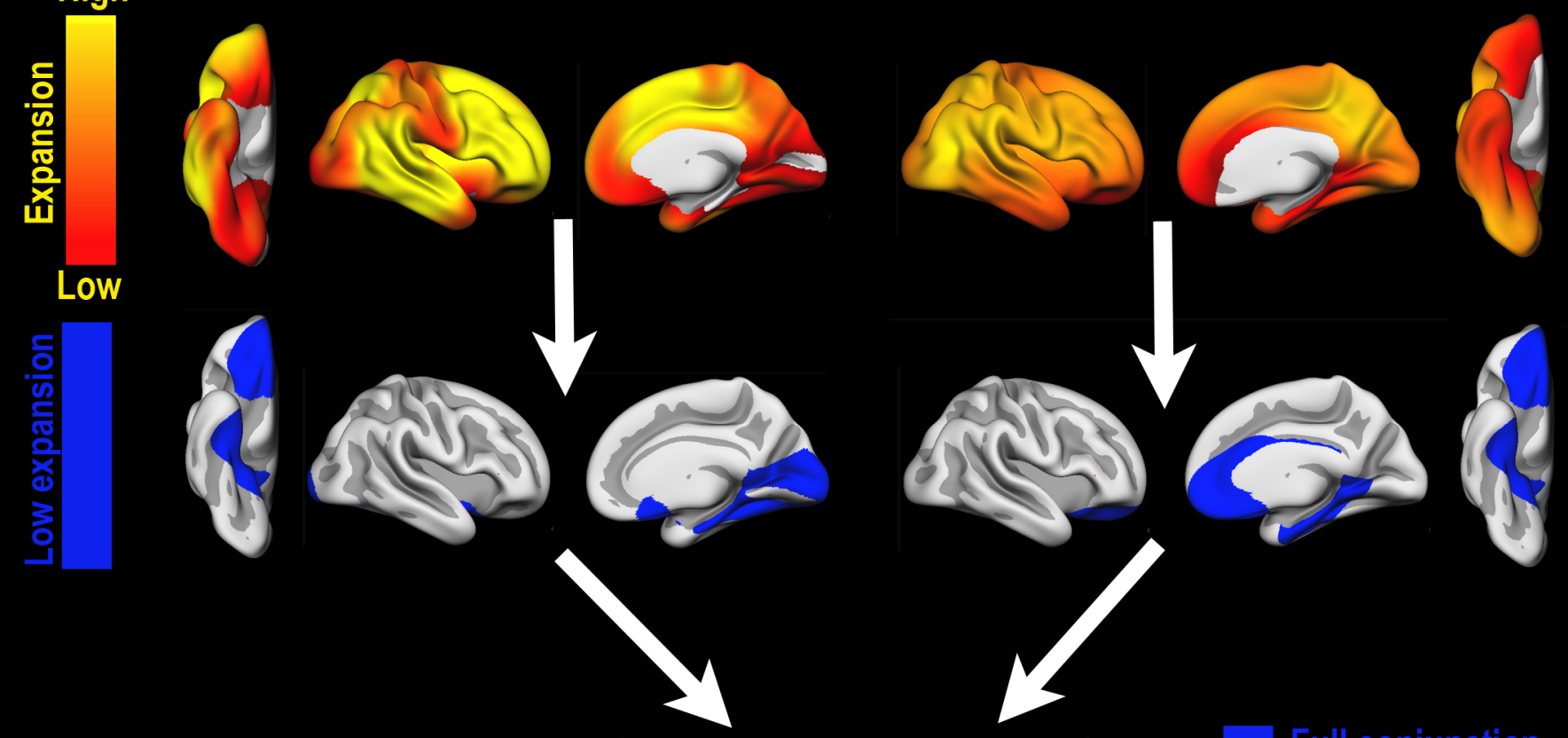

High
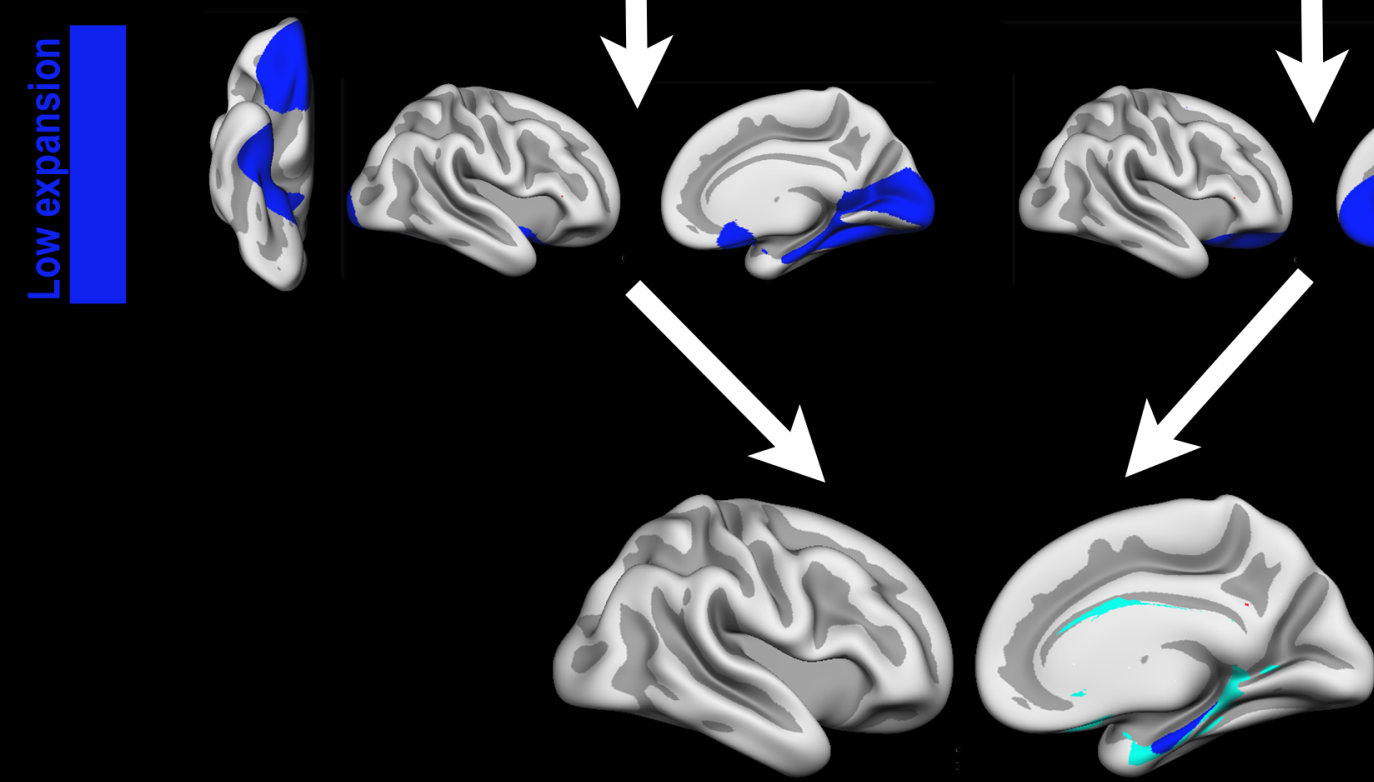

Full conjunction

(Low expansion, low genetic correlation, high variability in thickness change and myelin content)

Low
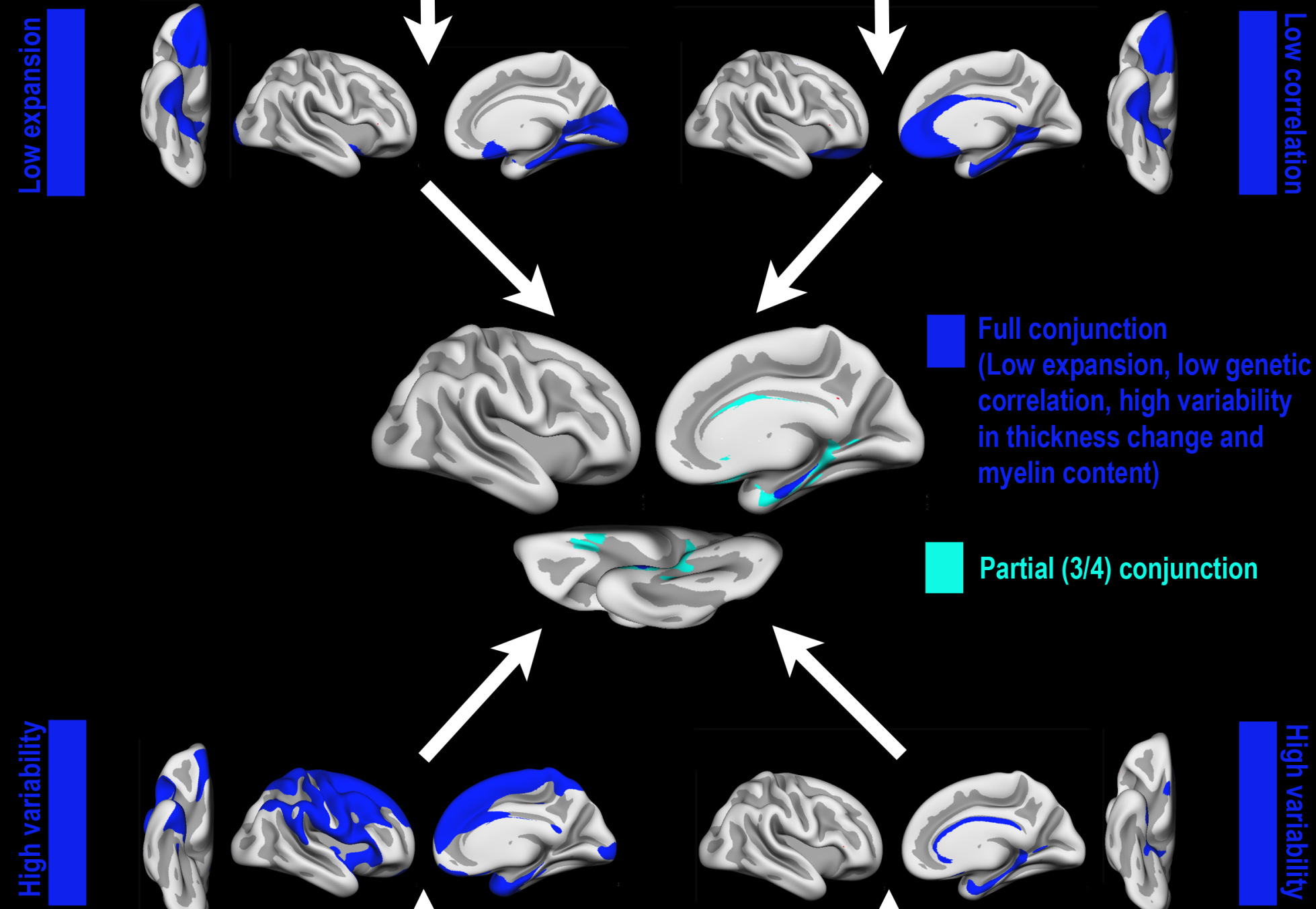

High

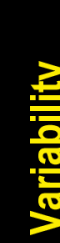
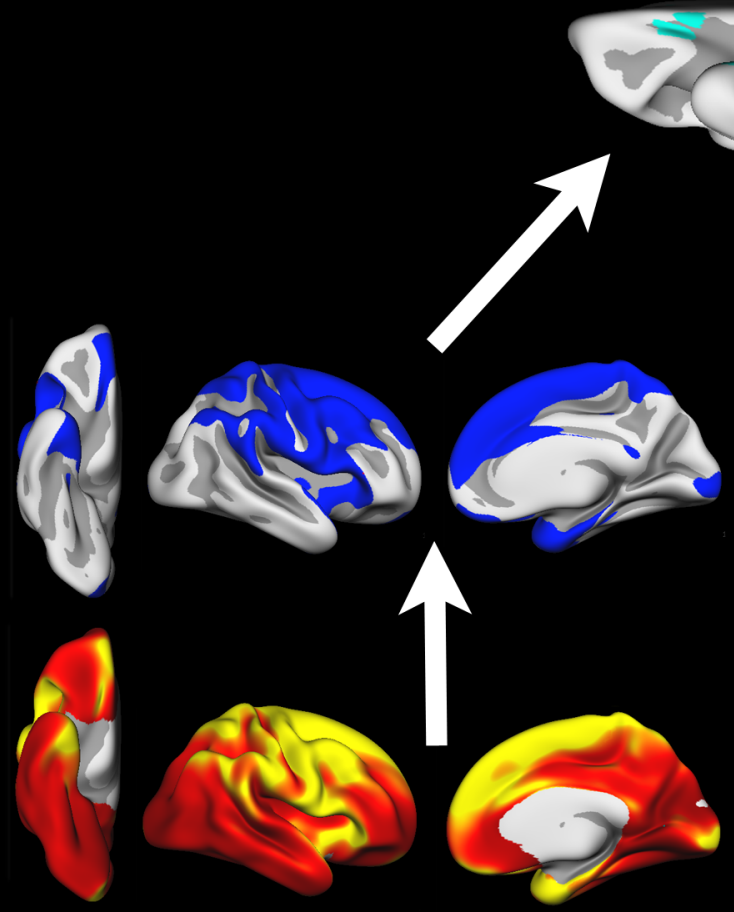

Thickness change variability

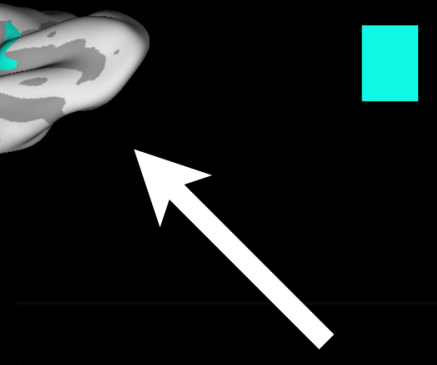

Partial (3/4) conjunction
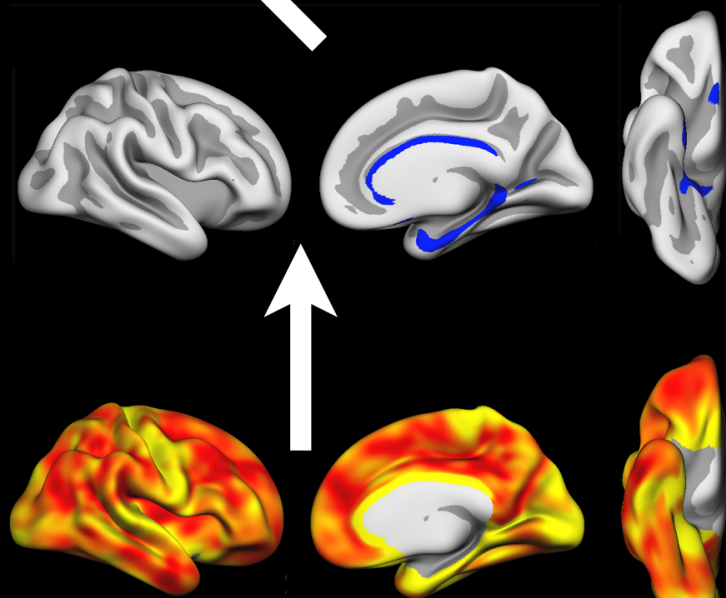

Low

Myelin variability

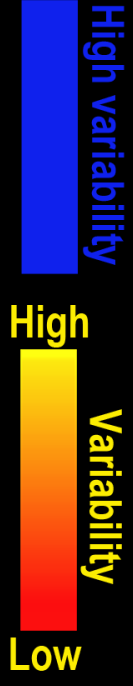


A
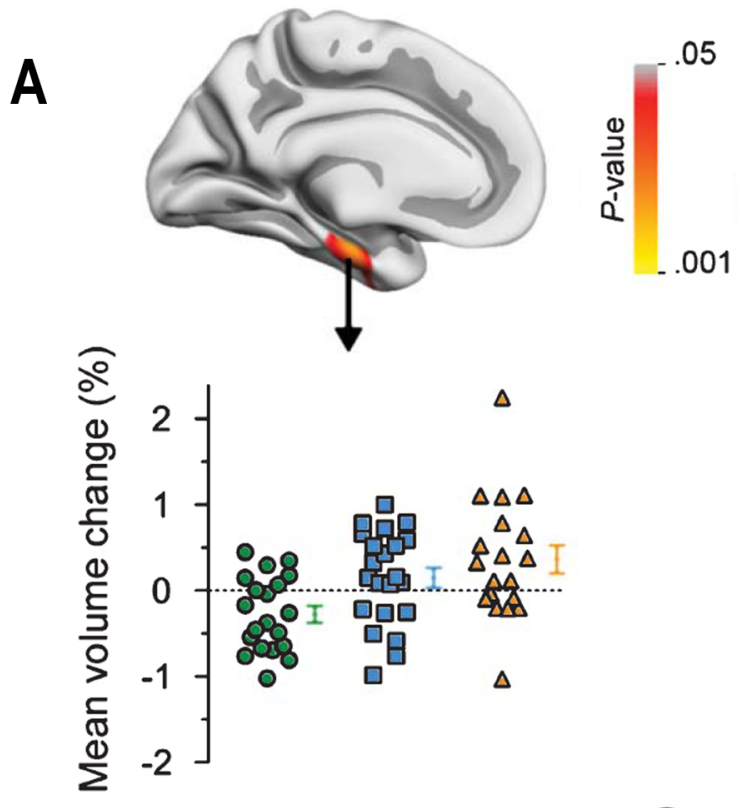

HC no-training $\mathrm{O}$

HC training $\square$

SMI training $\triangle$

Cortex

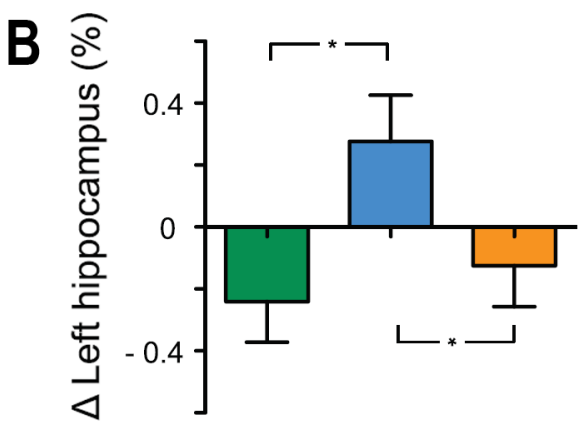

Hippocampus

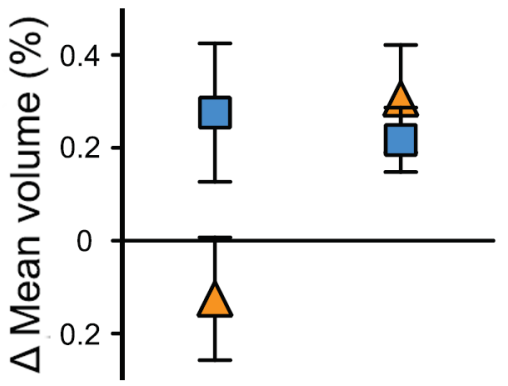

